\title{
Emerging therapies for the management of erectile dysfunction
}

\author{
Peter Pommerville MD FRCSC
}

P Pommerville. Emerging therapies for the management of erectile dysfunction. J Sex Reprod Med 2002;2(2):80-86.

Since the introduction of sildenafil, a phosphodiesterase type 5 (PDE-5) inhibitor, oral therapy is first-line therapy in the management of erectile dysfunction (ED). Two new PDE-5 inhibitors are under clinical development: vardenafil and tadalafil. These new agents appear to have advantages over sildenafil in the areas of time to onset of action, period of responsiveness, side effect profile, effectiveness in difficult to treat patient populations and interaction with food.

A centrally active sublingual agent recently released in Europe is effective in the treatment of mild and moderate ED. Apomorphine is a dopaminergic agonist that acts at the paraventricular nucleus in the hypothalamus.

In the present article, the benefits of these emerging therapies are reviewed.

Key Words: Apomorphine; Dopaminergic agonist; Erectile dysfunction; Paraventricular nucleus; Phosphodiesterase type 5 inhibitor; Tadalafil; Vardenafil

\section{Les traitements émergents dans la prise en charge de la dysfonction érectile}

RÉSUMÉ : Depuis l'homologation du sildénafil, un inhibiteur de la phosphodiestérase de type 5 (PDE-5), le traitement oral est le traitement de premier choix dans la prise en charge de la dysfonction érectile (DE). Deux nouveaux inhibiteurs de la PDE-5, le vardénafil et le tadalafil, sont en cours d'élaboration clinique. Ces nouveaux agents semblent comporter des avantages par rapport au sildénafil pour ce qui est du moment de l'action, de la période de réponse, du profil d'effets secondaires, de l'efficacité auprès des populations de patients difficiles à traiter et de l'interaction avec les aliments.

Un agent sublingual à action centralisée récemment implanté en Europe est efficace dans le traitement de la DE bénigne à modérée. L'apomorphine est un agoniste dopaminergique qui agit dans le noyau paraventriculaire de l'hypothalamus.

Dans le présent article, les bénéfices de ces traitements émergents sont examinés. 
$\mathrm{N}$ ewly available medical treatments for erectile dysfunction (ED), the increasing awareness of these new agents and a projected increase in the prevalence of ED worldwide are challenging issues for the future management of this disease. Patients and their partners are being encouraged more than ever to come forward with their sexual problems. More importantly, physicians are being encouraged to ask patients about their sex lives (1).

The effective treatment of ED has been made possible through an understanding of the physiology of erectile function. Of all the therapies available for the management of ED, oral therapy is preferred by most patients because of the simplicity of use, rapid and reliable effect, and lack of serious safety concerns.

While each form of oral therapy has its characteristic advantages and disadvantages, the selection of treatment for individual patients is judged according to their health status, as well as their cultural, personal, religious and financial situations (2).

Sildenafil (Viagra, Pfizer Inc, Canada), the first phosphodiesterase type 5 (PDE-5) inhibitor, set the stage for the development of new oral therapies for the management of ED, which led to the development of two new PDE-5 inhibitors - vardenafil (Nuviva, Bayer Inc, USA) and tadalafil (Cialis, ICOS LLC, USA). Further research has led to the development of a centrally acting oral medication for the treatment of ED. Apomorphine (Uprima, Abbott Laboratories, USA) is an effective sublingual thera- py for properly selected patients. A summary comparison of these medications is shown in Table 1.

\section{NEW PDE-5 INHIBITORS}

\section{Mechanism of action}

All PDE-5 inhibitors work in the same manner. Sexual stimulation results in the release of nitric oxide, which stimulates the production of cyclic guanosine monophosphate (cGMP). cGMP relaxes smooth muscle and promotes the inflow of arterial blood into the corpus cavernosal bodies. PDE-5 is the enzyme that breaks down cGMP in the corpus cavernosum. Therefore, any PDE-5 inhibitor increases cGMP levels and promotes the establishment of an erection after satisfactory sexual stimulation.

\section{Vardenafil}

Vardenafil is a highly selective, orally bioavailable PDE-5 inhibitor that is currently in development by Bayer and GlaxoSmithKline for the treatment of ED.

Pharmacokinetics and pharmacodynamics: Vardenafil is five to 10 times more potent than sildenafil, is more selective for PDE-5 than for PDE-1, and is more selective for PDE-6 than is sildenafil (3). There is also minimal crossreactivity of vardenafil with $\mathrm{PDE}-11$. Vardenafil is rapidly absorbed, with a time to maximum plasma concentration of $0.7 \mathrm{~h}$ and an elimination half-life of approximately $4.0 \mathrm{~h}$ $(4,5)$.

TABLE 1

Comparison of apomorphine*, sildenafil ${ }^{\dagger}$, tadalafil ${ }^{\ddagger}$ and vardenafil§

\begin{tabular}{|c|c|c|c|c|}
\hline & Apomorphine & Sildenafil & Tadalafil & Vardenafil \\
\hline Mechanism of action & $\begin{array}{l}\text { Central dopaminergic } \\
\text { receptor agonist }\end{array}$ & $\begin{array}{l}\text { Peripheral PDE-5 } \\
\text { inhibitor }\end{array}$ & $\begin{array}{l}\text { Peripheral PDE-5 } \\
\text { inhibitor }\end{array}$ & $\begin{array}{l}\text { Peripheral PDE-5 } \\
\text { inhibitor }\end{array}$ \\
\hline Onset of action & $\begin{array}{c}71 \% \text { get erections } \\
\text { within } 20 \mathrm{~min}\end{array}$ & $60 \mathrm{~min}$ & $\begin{array}{l}35 \% \text { get erections } \\
\text { within } 16 \mathrm{~min} ; \\
80 \% \text { within } 30 \mathrm{~min}\end{array}$ & $\begin{array}{c}50 \% \text { get erections } \\
\text { within } 30 \mathrm{~min}\end{array}$ \\
\hline Duration of responsiveness & $3 \mathrm{~h}$ & $<4 \mathrm{~h}$ & Up to $36 \mathrm{~h}$ & Up to $6 \mathrm{~h}$ \\
\hline Administration & Sublingual & Oral & Oral & Oral \\
\hline Frequency of use & Daily, as needed & Daily (once every 24 h) & Daily & Daily (once every 24 h) \\
\hline Efficacy (response) & $\begin{array}{l}60 \% \text { in those with } \\
\text { mild to moderate ED }\end{array}$ & $\begin{array}{l}73 \% \text { in those with } \\
\text { moderate to severe ED }\end{array}$ & $\begin{array}{l}68 \% \text { in diabetics; } \\
81 \% \text { in those with } \\
\text { mild to severe ED }\end{array}$ & $\begin{array}{l}72 \% \text { in diabetics; } \\
85 \% \text { in those with } \\
\text { mild to severe ED; } 65 \% \text { in } \\
\text { postradical prostatectomy } \\
\text { patients }\end{array}$ \\
\hline Side effects & $\begin{array}{l}\text { Nausea } 7 \% ; \\
\text { syncope } 3 \%\end{array}$ & $\begin{array}{l}\text { Headache, flushing, } \\
\text { blue vision, dyspepsia, } \\
\text { rhinitis }\end{array}$ & $\begin{array}{l}\text { Headache } 5 \% \\
\text { dyspepsia } 6 \% \\
\text { back pain } 3 \%\end{array}$ & $\begin{array}{c}\text { Headache } \leq 8 \% \\
\text { flushing } \leq 10 \% \\
\text { dyspepsia } \leq 5 \% \\
\text { rhinitis } \leq 6 \%\end{array}$ \\
\hline Safe with nitrates & Yes & Contraindicated & Contraindicated & Contraindicated \\
\hline Interaction with food or alcohol & None & Yes & None & Meal \\
\hline
\end{tabular}

*Uprima, Abbott Laboratories, USA; †Viagra, Pfizer Inc, Canada; ¥Cialis, Lilly ICOS LLC, USA; §Nuviva, Bayer Inc, USA. ED Erectile dysfunction; PDE-5 Phosphodiesterase type 5 
The pharmacodynamic properties of vardenafil have been demonstrated in randomized, double-blind, placebo controlled studies in men with ED of mixed etiology. Klotz et al (4) showed that vardenafil, in doses of $10 \mathrm{mg}$ and $20 \mathrm{mg}$, significantly increased the rigidity and duration of erections compared with placebo $(\mathrm{P}<0.001)$, as measured with RigiScan (Timm Medical Technologies, USA) during visual sexual stimulation. The $20 \mathrm{mg}$ dose shows a bioavailability that is comparable with that of the $10 \mathrm{mg}$ dose (4). Similar results were observed in a separate study by Stark et al (5). Adverse events included headache, flushing and nasal congestion, and treatments were generally well tolerated.

Safety and efficacy: Vardenafil's safety and efficacy were evaluated in one large phase II and four phase III clinical trials involving more than 2800 patients. In the phase II, large scale, at-home study, 601 men with mild to severe ED were randomly assigned to 12 weeks of therapy with placebo, or with $5 \mathrm{mg}, 10 \mathrm{mg}$ or $20 \mathrm{mg}$ of vardenafil (6). The primary end points of this study were question 3 (vaginal penetration) and question 4 (maintenance of erection) of the International Index of Erectile Function (IIEF). Changes from baseline for all doses of vardenafil were improved for question 3 (compared with placebo, $\mathrm{P}<0.001$ ) and for question 4 (compared with placebo, $\mathrm{P}<0.001$ ).

Eighty per cent of the patients taking the $20 \mathrm{mg}$ dose experienced improved erections compared with 30\% who received placebo, as indicated by responses to the Global Assessment Question (GAQ) ("Has the treatment you have been taking over the past four weeks improved your erections?"). The observed improvements were irrespective of age, etiology and baseline severity. More importantly, the effectiveness of vardenafil was maintained throughout the 12-week study period (7). The rates of incidence of adverse events, the most common of which were headache, dyspepsia and flushing, were highest in the first four weeks, and declined or were stable throughout the duration of the study. The incidence of headache in the initial month was $11.5 \%$ in patients taking the the $20 \mathrm{mg}$ dose, and decreased to $8 \%$ by the last month. The incidence of flushing was consistent throughout the study, ranging between $6 \%$ and $10 \%$ for all doses. Dyspepsia had the highest incidence rate in the first month, occuring in 5\% in those taking $20 \mathrm{mg}$, and decreased to $2 \%$ in the last month. There were no drugrelated serious adverse events (7).

The North American phase III clinical trial with vardenafil was conducted in 60 centres in Canada and the United States. Patients with varied etiologies, severities and comorbidities were randomly assigned to 26 weeks of treatment with either placebo or $5 \mathrm{mg}, 10 \mathrm{mg}$ or $20 \mathrm{mg}$ of vardenafil (8). Vardenafil significantly improved penetration and maintenance of erections in patients with a wide range of ED severity. Of those completing 26 weeks of treatment, improved erections were noted by $85 \%, 80 \%$ and $65 \%$ of men treated with vardenafil $20 \mathrm{mg}, 10 \mathrm{mg}$ and $5 \mathrm{mg}$, respectively, compared with $28 \%$ of men treated with placebo $(\mathrm{P}<0.0001)$. Of significance is that, with $20 \mathrm{mg}$ of var- denafil, $79 \%$ of patients with mild $\mathrm{ED}$ at baseline returned to normal (compared with $21 \%$ in the placebo group), and $39 \%$ of patients with severe ED at baseline returned to normal (compared with $4 \%$ in the placebo group) (9). As noted above, the adverse events were mild to moderate, with headache, flushing, rhinitis and dyspepsia being the most frequent complaints.

Diabetes mellitus: Patients with diabetes mellitus have a higher incidence of ED and are known to be generally less responsive to the available oral ED therapies. A doubleblind, randomized, placebo controlled study of vardenafil was conducted in men with ED and diabetes mellitus. This study was undertaken in 47 centres in Canada and the United States $(10,11)$.

A total of 452 men participated in a four-week baseline period and were randomly assigned to a 12 -week period of treatment with either placebo, or $10 \mathrm{mg}$ or $20 \mathrm{mg}$ of vardenafil. The GAQ responder rate was $72 \%$ for the group that received vardenafil $20 \mathrm{mg}$ and $13 \%$ for the placebo group $(\mathrm{P}<0.0001)$. Both doses of vardenafil significantly improved erectile function (IIEF) domain scores (19.0 for $20 \mathrm{mg}$ dose versus 12.6 for placebo, $\mathrm{P}<0.0001)$ as well as the rates of successful penetrations and maintenance of erection to intercourse completion, compared with placebo. Vardenafil $10 \mathrm{mg}$ and $20 \mathrm{mg}$ doses were very effective in improving erectile function for all primary efficacy variables in diabetic men with ED. In addition, vardenafil was well tolerated in this diabetic population with mild to moderate adverse events that were transient in nature.

Radical prostatectomy: ED is a common complication found in patients following radical retropubic prostatectomy. In the first international multicentre trial of its kind, the use of drug therapy to improve erectile function after nerve-sparing radical prostatectomy was initiated in Canada. It was conducted in 65 centres in Canada and the United States (12).

In this double-blind, placebo controlled study, men with ED following a nerve-sparing radical retropubic prostatectomy six months to five years before the study were randomly assigned to a 12-week treatment with placebo, or vardenafil $10 \mathrm{mg}$ or $20 \mathrm{mg}$. The mean baseline scores of erectile function (IIEF-EF) indicated severe ED (9.1 to 9.3). With vardenafil treatment, the IIEF-EF scores were significantly improved (15.3 for $10 \mathrm{mg}$ and $20 \mathrm{mg}$ versus 9.2 for placebo, $\mathrm{P}<0.0001)$, and rates of partner penetration and erection maintenance were also significantly increased $(\mathrm{P}<0.0001)$ for all primary efficacy measures, irrespective of baseline severity.

Of patients completing the three months of treatment, $65 \%$ and $59 \%$ reported an improvement in erections with $20 \mathrm{mg}$ and $10 \mathrm{mg}$ doses, respectively. The adverse events profile was similar to that of other studies, and there were no reports of blue vision.

Cardiovascular safety: ED is very common among men with coronary artery disease (CAD), and there is a small but finite risk of developing ischemia with sexual activity in these patients. A multicentre study was conducted in 
patients with stable cardiac ischemia to evaluate the effects of vardenafil in patients undergoing an exercise treadmill test during physical exercise at a level similar to or greater than that of sexual activity (13).

In this study, 41 men with stable ischemic CAD received single doses of vardenafil $10 \mathrm{mg}$ or placebo, and an exercise treadmill test was performed $1 \mathrm{~h}$ after dosing at the expected time of maximum drug exposure. The total exercise treadmill time and time to awareness of angina pectoris were not affected by vardenafil compared with placebo. Moreover, time to ST-segment depression was slightly improved compared with placebo $(\mathrm{P}=0.0004)$. This study demonstrated that vardenafil $10 \mathrm{mg}$ does not affect the ability of patients with stable CAD to exercise at a level exceeding that that is usually required for sexual activity.

A randomized, placebo controlled crossover study was also conducted to look at the interaction between nitroglycerin (NTG) and vardenafil in 18 healthy middle-aged men (14). Blood pressure (BP) and heart rate (HR) were measured while the men were seated. NTG administration $1 \mathrm{~h}$ after vardenafil treatment was associated with minimal changes in $\mathrm{BP}$ and $\mathrm{HR}$ that were comparable with those seen following NTG and placebo administration. In all cases, the combination of agents was well tolerated.

A pooled analysis of large phase III trials in the broad population of patients with ED showed that vardenafil was highly effective, regardless of the use of various antihypertensive medications (15). The percentages of patients using various types of different antihypertensives were: diuretic $14 \%$; beta-blocker $18 \%$; calcium channel blockers $18 \%$; angiotensin-converting enzyme inhibitors $36 \%$; and others $14 \%$. At all doses, vardenafil significantly improved the IIEF-EF domain, and Sexual Encounter Profile (SEP) questions 2 and 3, compared with placebo, regardless of whether patients were taking an antihypertensive $(\mathrm{P}<0.001)$. Vardenafil was well tolerated in all situations, with only very minimal $\mathrm{BP}$ changes, regardless of whether antihypertensive medications were being used. Also, there were no recorded clinically significant elevations in HR in the vardenafil-treated patients.

Summary: Vardenafil is highly recommended for the treatment of ED. It has demonstrated significant proven efficacy in difficult to treat patient populations, namely in postradical prostatectomy patients and those with diabetes mellitus. Vardenafil has a fast onset of action, minimal interaction with food and alcohol, and generally mild and well tolerated side effects (Table 1).

\section{Tadalafil}

Tadalafil is a very potent and highly selective reversible inhibitor of PDE-5, and is administered orally. Tadalafil has been shown to be well tolerated and effective when administered on an as needed or daily basis for the treatment of ED (Eli Lilly, data on file).

Efficacy: In a recent study, Tadalafil was given to men older than 18 years of age with mild to severe ED of psychogenic, organic or mixed causes, and with a duration of three months or longer. Patients with a history of diabetes mellitus and radical prostatectomy were also included in the study. The doses of tadalafil in the 212 patients varied from $2 \mathrm{mg}$ to $25 \mathrm{mg}$. The primary end points were a change from baseline in the IIEF scores for questions 3 and 4, the SEP questions on vaginal penetration and maintenance of erection through intercourse (questions 2 and 3 , respectively) and the GAQ (Eli Lilly, data on file).

All doses of tadalafil were associated with significant improvement in the quality of erections compared with placebo, as assessed by the GAQ. The mean percentages of 'yes' responses were $62 \%, 57 \%, 68 \%$ and $88 \%$ for $2 \mathrm{mg}$, $5 \mathrm{mg}, 10 \mathrm{mg}$ and $25 \mathrm{mg}$, respectively, compared with $28 \%$ for placebo. Compared with placebo, tadalafil at $2 \mathrm{mg}$ to 25 $\mathrm{mg}$ produced significant dose-dependent improvements in erectile function, as measured by IIEF-EF domain scores. The mean changes from baseline to end points were -0.22 for the placebo group versus 4.22 ( $2 \mathrm{mg}$ ), 5.88 ( $5 \mathrm{mg}$ ), 7.10 $(10 \mathrm{mg})$ and $9.93(25 \mathrm{mg})$ for the tadalafil treatment groups. All of the doses of tadalafil, as assessed by IIEF question 3 , were associated with significant improvements in penetration ability compared with placebo $(\mathrm{P}<0.001,5 \mathrm{mg}$ to $25 \mathrm{mg}$ ). The mean changes from baseline to end points were -0.32 for the placebo group versus 0.57 ( $2 \mathrm{mg}$ ), 0.86 ( 5 $\mathrm{mg}), 0.98(10 \mathrm{mg})$ and $1.49(25 \mathrm{mg})$ for the tadalafil treatment groups.

Compared with placebo, tadalafil at doses of $5 \mathrm{mg}$ to $25 \mathrm{mg}$ produced significant improvement in the patients' ability to maintain their erections as determined by IIEF question 4 . The greatest improvements from baseline were observed in the $10 \mathrm{mg}$ and $25 \mathrm{mg}$ treatment arms of the study (16).

In a separate study of men with diabetes mellitus and ED, tadalafil led to a significant improvement in erectile function. Compared with placebo, tadalafil $10 \mathrm{mg}$ and $20 \mathrm{mg}$ improved erections significantly $(\mathrm{P}<0.001)$, as assessed by GAQ question 1 among the three treatment groups. There was a significant difference in the percentage of 'yes' responses to GAQ question 1 among the three treatment groups: placebo (25\%), tadalafil $10 \mathrm{mg}(56 \%)$ and tadalafil $20 \mathrm{mg}$ (64\%). Similar significant differences were observed in all three treatment groups in response to GAQ question 2 (the ability to engage in sexual activity): $20 \%$ in the placebo group, $51 \%$ in the $10 \mathrm{mg}$ tadalafil group and $58 \%$ in the $20 \mathrm{mg}$ tadalafil group (Eli Lilly, data on file).

Tadalafil also increased erectile function in diabetic men, as assessed by the IIEF. Both $10 \mathrm{mg}$ and $20 \mathrm{mg}$ doses of tadalafil improved erectile function, as assessed by the change from baseline in the IIEF domain score $(\mathrm{P}<0.0001$, compared with placebo), with the $20 \mathrm{mg}$ treatment group achieving a greater than five-point change from baseline to end point. Both tadalafil $10 \mathrm{mg}$ and $20 \mathrm{mg}$ improved penetration ability (IIEF, question 3 ) and the ability to maintain an erection during intercourse (IIEF, question 4) $(\mathrm{P}<0.0001$ compared with placebo).

In the study of diabetic men (Eli Lilly, data on file), tadalafil also increased the percentage of successful sexual 
intercourse attempts, as assessed by the patients' SEP scores. Both $10 \mathrm{mg}$ and $20 \mathrm{mg}$ doses improved the percentage of positive attempts at vaginal penetration (SEP, question 2) and also improved the percentage of successful intercourse attempts (SEP, question 3). The percentages of patients achieving more than a $25 \%$ increase in 'yes' responses to SEP question 2 and SEP question 3 were greater for the $20 \mathrm{mg}$ tadalafil treatment group than for the $10 \mathrm{mg}$ tadalafil treatment group. Thus, tadalafil use led to improvements in IIEF domain scores regardless of diabetes type, current diabetic therapy, initial level of glycemic control or the presence of microvascular complications (Eli Lilly, data on file). Safety: All doses of tadalafil appear to be well tolerated. In particular, the $10 \mathrm{mg}$ and $20 \mathrm{mg}$ doses were well tolerated in the diabetic population. The safety of tadalafil has been evaluated in 16 clinical trials, with a total of 3249 patients enrolled. Tadalafil is rapidly absorbed after oral administration, and is predominately eliminated by the liver and distributed into the tissues. Within 30 min of dosing, mean plasma tadalafil concentrations are expected to exceed the IC 50 needed for half-maximal inhibition of PDE-5. The time to maximum concentration of tadalafil is $2 \mathrm{~h}$, and the half-life is $17.5 \mathrm{~h}$. The long half-life of tadalafil is associated with a period of responsiveness for tadalafil of up to $24 \mathrm{~h}$ or more after dosing. In a double-blind controlled study evaluating the efficacy of the $20 \mathrm{mg}$ dose at $24 \mathrm{~h}$ and $36 \mathrm{~h}$, $57.3 \%$ of intercourse attempts by tadalafil-treated men were successful $24 \mathrm{~h}$ after dosing compared with $31.3 \%$ of attempts in placebo-treated men, $(\mathrm{P}<0.0001)$. At $36 \mathrm{~h}$, $60.4 \%$ of intercourse attempts by tadalafil-treated men were successful compared with $29.9 \%$ of attempts by placebotreated men $(\mathrm{P}<0.0001)(17)$.

The earliest recorded time to onset when tadalafil $20 \mathrm{mg}$ was found to be statistically significantly different from placebo (measured by SEP question 3) was 16 min after dosing, occurring in $35 \%$ of patients. At $30 \mathrm{~min}$ after dosing, $52 \%$ of men taking tadalafil $20 \mathrm{mg}$ were found to be responders. Among the responders, $47 \%$ of all tadalafil $20 \mathrm{mg}$ doses resulted in an erection within $20 \mathrm{~min}, 61 \%$ within $25 \mathrm{~min}$ and $80 \%$ within $30 \mathrm{~min}$ (18).

Despite that tadalafil is metabolized by the liver, the presence of mild to moderate hepatic impairment did not compromise the metabolic clearance of tadalafil. In other words, the data suggest that an adjustment of the dose of tadalafil is not warranted. Similarly, the presence of renal failure does not appear to alter the pharmacokinetic properties sufficiently to warrant a dose adjustment. Extrinsic factors such as food, alcohol and the timing of the dose of tadalafil have no clinically relevant effect on the pharmacokinetics of tadalafil. Therefore, tadalafil can be administered without regard for food or alcohol consumption, or the time of day (Eli Lilly, data on file).

Tadalafil displays a high degree of selectivity toward PDE-5 compared with other PDE isoforms. The closely related PDE-6 enzyme found in the human retina displayed a greater than 700 -fold lower affinity for tadalafil (Eli Lilly, data on file). All of the other human PDEs showed a greater than 10,000-fold lower affinity for tadalafil. Tadalafil has a fivefold higher selectivity for PDE-11 than does vardenafil. The physiological role of PDE-11 and the consequence of its inhibition have not been established. PDE-11 inhibition is thought to be responsible for the side effects of back pain and myalgia (19). While colour visual disturbance is not a significant side effect, its absence gives the patient a perception that tadalafil is safer. Tadalafil can be used in different ways - to achieve an erection in a short time, or it can be taken in preparation for sexual activity at a later time, effectively restoring the spontaneity of sexual activity.

Tadalafil $20 \mathrm{mg}$ in healthy subjects resulted in no significant difference, compared with placebo, in standing systolic or diastolic blood pressure (mean maximal decrease of $0.2 / 4.6 \mathrm{mmHg}$ ), and no change in heart rate. The incidence rate of myocardial infarction in tadalafil across all clinical studies (more than 4000 patients) was 0.39/100 patientyears, compared with $1.1 / 100$ patient-years in placebotreated patients (more than 1200) (20).

The reported side effects of tadalafil have been mild to moderate in intensity and have attenuated over time. There have been no treatment-related serious adverse events with tadalafil. Dyspepsia and headache were the only treatment-related adverse events reported by $75 \%$ of all tadalafil-treated patients. The adverse events reported were similar for $10 \mathrm{mg}$ and $20 \mathrm{mg}$ doses, and did not appear to be dose dependent. Unlike sildenafil, facial flushing was not reported with tadalafil use. However, some studies did report the presence of unexpected back pain in 3\% of patients, but the back pain was also noted to diminish with repeated dosing of tadalafil (21).

Studies have been performed to investigate the pharmacodynamic interactions between tadalafil and nitrates. Despite the modest additive effect of tadalafil on nitrateinduced reductions in mean maximal systolic and diastolic pressures, the frequency of significant blood pressure effects indicates that, as with sildenafil, tadalafil should not be used in conjunction with nitrates (Eli Lilly, data on file,22). Summary: Tadalafil $10 \mathrm{mg}$ and $20 \mathrm{mg}$ orally is an effective treatment option for men with ED. Tadalafil can restore spontaneity to a couple's relationship because of its prolonged period of responsiveness (at least $24 \mathrm{~h}$ after dosing). Tadalafil is absorbed rapidly, has a low hepatic clearance, and its side effects are mild with attenuation over time. The most common adverse event is headache (Table 1).

\section{APOMORPHINE: \\ A CENTRALLY ACTING ORAL ED THERAPY}

Apomorphine is indicated for the first-line management of ED. In contrast to PDE-5 inhibitors that act at the level of the corpus cavernosum of the penis, apomorphine acts exclusively in the central nervous system (23). Apomorphine is a dopamine receptor agonist. Apomorphine is not an opioid; therefore, it does not cause addiction or result in the narcotic effects that are often seen with morphine.

Apomorphine acts at the level of the hypothalamus. The primary area involved in the neural initiation of the penile 
erection is the paraventricular nucleus (PVN) of the hypothalamus. The PVN is influenced by positive (erectogenic) and negative (erectolytic) signals from the cerebral cortex. Erectogenic stimuli include imagination and visual, olfactory and tactile stimuli. The negative or inhibitory erectolytic stimuli include anxiety, fear and depression. The release of the neurotransmitter dopamine in the PVN is the major stimulus in the central mechanism of penile erection. The released dopamine stimulates $D_{2}$ receptors, leading to the transmission of erectile signals through the midbrain to the descending parasympathetic pathways of the sacral spinal cord. These signals activate pelvic nerves supplying the pelvis and serve to relax the vascular smooth muscle of the penile corporal bodies, resulting in a rigid penile erection (24).

Based on its central mechanism of action, sublingual delivery of apomorphine facilitates a rapid time of onset of erection that is similar to the natural erectile response. The sublingual tablet formulation allows for apomorphine to be rapidly absorbed. Detectable plasma concentrations are observed within $10 \mathrm{~min}$ and the time to maximum concentration was determined to be 40 to $60 \mathrm{~min}$ (25). This formulation allows the drug to reach therapeutic levels in the blood while minimizing the side effects associated with other routes of administration (26). In patients who responded to treatment, more than $71 \%$ of erections occurred within 20 min of sublingual administration (27). In addition to rapid absorption, the sublingual delivery avoids first-pass metabolism; therefore, apomorphine is not affected by food.

Apomorphine is metabolized through the conjugation with glucouronic acid or sulphate, or via $N$-demethylation to form norapomorphine. Following sublingual delivery, apomorphine is rapidly cleared, with an elimination halflife of 2 to $3 \mathrm{~h}$. Only 20\% of apomorphine is metabolized by the cytochrome P450 (CYP450) system. Thus, the low plasma concentrations and rapid clearance minimize the potential for drug interactions (28).

\section{Dosage}

In phase III, double-blind, placebo controlled studies, ED patients taking apomorphine $2 \mathrm{mg}$ and $3 \mathrm{mg}$ had a significantly greater percentage of erections that were firm enough for intercourse compared with those taking placebo. Two studies compared the $2 \mathrm{mg}$ dose with placebo, and the third study compared the $3 \mathrm{mg}$ dose with placebo. In the first comparison, $45.5 \%$ of patients receiving the $2 \mathrm{mg}$ dose achieved erections that were firm enough for intercourse compared with $34.6 \%$ of patients taking placebo $(\mathrm{P}<0.001)$. The intercourse rate (ie, the proportion of successful attempts at intercourse) was also higher in those taking the $2 \mathrm{mg}$ dose compared with those taking placebo (43.3\% and 33.2\%, respectively, $\mathrm{P}<0.001$ ) (29). Similarly, the percentage of patients achieving erections with $3 \mathrm{mg}$ doses was statistically higher than the percentage of those receiving placebo $(46.9 \%$ and $32.3 \%, \mathrm{P}<0.001)$, as was the intercourse rate $(48.0 \%$ and $34.0 \%$ respectively, $\mathrm{P}<0.001)$ (30). Apomorphine also improved all secondary end point measures of erectile function, ie, all IIEF domain scores increased, except sexual desire, with apomorphine $3 \mathrm{mg}$ compared with placebo $(\mathrm{P}<0.001)$. In those patients who elected to receive long term treatment with apomorphine $2 \mathrm{mg}$ or $3 \mathrm{mg}$, and who stayed in the study for six months or longer, $92 \%$ of attempts resulted in erections firm enough for intercourse at one month, and the corresponding values for six, 12 and 18 months were approximately 90\%, 98\% and $88 \%$, respectively, thus providing long term satisfaction and reduced fear of failure for both the patient and the partner (29). The time to erection sufficient for penetration was within $10 \mathrm{~min}$ for $34 \%$ of patients, and within $20 \mathrm{~min}$ for $71 \%$ of patients. This parameter was not affected by the patient's age or by food intake (27).

Apomorphine has been administered to patients with mild, moderate and severe ED, as defined by their IIEF scores. Apomorphine demonstrated its greatest efficacy in patients with mild to moderate ED, with $60 \%$ of all attempts resulting in an erection firm enough for intercourse $(\mathrm{P}<0.001)$. Also, it was demonstrated that apomorphine treatment results in improved erectile function in patients with coexisting conditions such as hypertension, CAD, benign hyperplasia of the prostate and diabetes (29).

The likelihood of achieving an erection with successful intercourse increases with sequential dosing of apomorphine $3 \mathrm{mg}$. At least four doses at $3 \mathrm{mg}$ are recommended. Side effects are also minimized if the dose is titrated (ie, starting at $2 \mathrm{mg}$ sublingually and progressing by sequential dosing to $3 \mathrm{mg}$ ).

\section{Safety and tolerability}

Apomorphine has been shown to be safe and relatively well tolerated in patients with comorbid conditions and concomitant medications. Apomorphine safety and tolerability have been assessed in more than 5000 patients in 33 clinical trials (Abbot Laboratories, data on file). The reported adverse events were mild, transient and self-limiting. At $2 \mathrm{mg}$ and $3 \mathrm{mg}$ doses of apomorphine, less than $14 \%$ of patients experienced adverse events. With a dose of $3 \mathrm{mg}$ of apomorphine, the most common adverse event was nausea, at $7 \%$, and the incidence of nausea was reduced during the sequential use of apomorphine $3 \mathrm{mg}$. Nausea was noted to have little or no occurrence by the eighth administration. Nausea was also mild and transient, with an antiemetic needed in only $0.7 \%$ of cases in which nausea was present (29).

The incidence of syncope is dose related and occurred in less than $0.2 \%$ of patients taking $2 \mathrm{mg}$ and $3 \mathrm{mg}$ of apomorphine (28). More than $90 \%$ of the reported cases of syncope were preceded by symptoms of nausea, sweating and dizziness. There have been no drug-related deaths, myocardial infarctions, cerebrovascular events or priapisms reported with the administration of apomorphine. It has been noted that $3 \%$ of patients discontinued the use of apomorphine because of adverse events. Apomorphine has not demonstrated any interaction with nitrates, antidepressants or antihypertensives (29). 


\section{Summary}

Apomorphine has a favourable safety and tolerability profile (Table 1). Combined with its consistent efficacy and ability to restore spontaneity, apomorphine can be an effective treatment in mild to moderate ED.

\section{REFERENCES}

1. Brock G. Erectile dysfunction: educational forum - I. Can J Urol 2001;8:1416-8.

2. Jordin A, Wagner G, Khoury F, et al. Erectile Dysfunction. Plymouth: Health Publication Ltd, 2000:709-26.

3. Saenz de Tejada I, Angulo J, Cuevas P, et al. The phosphodiesterase inhibitory selectivity and the in vitro and in vivo potency of the new PDE 5 inhibitor vardenafil. Int J Impot Res 2001;31:282-90.

4. Klotz T, Sachse R, Heidrich A, et al. Vardenafil increases penile rigidity and tumescence in erectile dysfunction patients: A RigiScan and pharmacokinetic study. World J Urol 2001;19:32-9.

5. Stark S, Sachse R, Liedl T, et al. Vardenaril increases penile rigidity and tumescence in men with erectile dysfunction after a single oral dose. Eur Urol 2001:40:181-90.

6. Porst H, Rosen R, Padma-Nathan H, et al. The efficacy and tolerability of vardenafil, a new, oral, selective phosphodiesterase type 5 inhibitor, in patients with erectile dysfunction: The first at-home clinical trial. Int J Impot Res 2001;13:192-9.

7. Young J, Auerbach S, Porst H. Vardenafil, a new selective PDE5 inhibitor, significantly improved all IIEF domains and showed favorable safety profile in patients with erectile dysfunction over 12 weeks. J Urol 2001;165(Suppl 5):224.

8. Hellstrom, Gittelman M, Shapiro J, et al. Vardenafil improved erectile function in men with a broad range of erectile dysfunction etiologies and severities: A phase III trial. Int J Impot Res 2001;13(Suppl 5):S65.

9. Hellstrom W, Gittelman M, Shapiro J, et al. Efficacy and safety of vardenafil in men with erectile dysfunction: the North American (NA) pivotal placebo-controlled trial. J Urol 2002;167(Suppl):(Abst)

10. Goldstein I, Young J, Fischer J. Vardenafil: a new highly selective PDE 5 inhibitor, improves erectile function in patients with diabetes mellitus. Diabetes 2001;50(Suppl 2):A114.

11. Goldstein I, Young J, Fischer J. Vardenafil: a new selective PDE 5 inhibitor, significantly improved all IIEF domains and showed favorable safety profile in patients with impaired erectile function and diabetes mellitus. Int J Impot Res 2002;13(Suppl 5):S64

12. Brock G, Padma-Nathan H, Seger M. Efficacy and tolerability of vardenafil in men with erectile dysfunction following radical prostatectomy. Eur Urol 2002;1(Suppl 1):152.

13. Thadani U, Mazzu A. Exercise-induced ischemia was not adversely affected by vardenafil during exercise stress test in men with coronary artery disease. Eur Urol 2002;1(Suppl 1):151.

14. Mazzu A, Nicholls A, Zinny M. Vardenafil, a new selective PDE-5 inhibitor, interacts minimally with nitroglycerin in healthy middleaged male subjects. Int J Impot Res 2001;13(Suppl 5):S64

15. Harmut P, Padma-Nathan H, Tionnier. Efficacy and safety of vardenafil, a selective phosphodiesterase 5 inhibitor in men with erectile dysfunction on antihypertensive therapy. American Society of Hypertension Meeting, 2002.

16. Brock G, Iglesias J, Toulouse K, et al . Efficacy and safety of IC351 treatment for ED. Eur Urol 2001;39(Suppl 5):106. (Abst)

17. Padma-Nathan H, Auerbach S, Lewis R, et al. Efficacy and safety of apomorphine SL vs. placebo for male erectile dysfunction. J Urol 2001;165 (Suppl):224. (Abst)

18. Angling G, Inglesias J, Toulouse K. Efficacy and safety of IC 351 in treatment for ED. Int J Impot Res 2001;12(Suppl 3);S75.

19. Gbekor E, Bethell S, Fawcett L, et al. Eur Urol 2002;1(Suppl 1):63.

20. Kloner RA, Watkins VS, Costigan TM, et al. Cardiovascular profile of tadalafil, a new PDE5 inhibitor. J Urol 2002;167(Suppl):176

21. Brock G. New PDE-5 Inhibitor Efficacious in Erectile Dsyfunction. Anaheim: Med Ed Network, Priority Press, 2001.

22. Kloner RA, Mitchell MI, Bedding A, et al. Pharmacodynamic interactions between tadalafil and nitrates compared with sildenafil. J Urol 2002;167 (Suppl):176.

23. Heaton JPW. Central neuropharmacological agents and mechanisms in erectile dysfunction; the role of dopamine. Neurosci Biobehav Rev 2000;24:561-9.

24. Adams MA. Uprima: The importance of neurophysiology and dopaminergic pathways in erectile function: Therapeutic targeting. Rio de Janeiro: Abbott Laboratories Publication, 2002:14

25. Argiolas A, Hedlund $\mathrm{H}$. The pharmacology and clinical pharmacokinetics of apomorphine SL. BJU International 2001;88:(Suppl 3):18-21.

26. Buvat J, Montorsi F. Safety and tolerability of apomorphine SL in patients with erectile dysfunction. BJU International 2001;88(Suppl 3):30-5.

27. Sleep DJ. Uprima: Clinical Efficacy. Rio de Janeiro: Abbott Laboratories Publication, 2001:18.

28. Heaton JPW. Uprima: Rational prescribing in ED therapy. Rio de Janeiro: Abbot Laboratories Publication, 2002:12.

29. Mirone VG, Stief CG. Efficacy of apomorphine SL in erectile dysfunction. BJU International 2001;88 (Suppl 3):25-9.

30. Dule E, Bukofzer S, Perdok R, et al. Double-blind, cross-over comparison of $3 \mathrm{mg}$ apomorphine SL with placebo and with $4 \mathrm{mg}$ apomorphine SL in male erectile dysfunction. Eur Urol 2001;39:558-64.

\section{Note from the Editor-in-chief}

The success of sildenafil is responsible for the introduction of a number of new therapies for the treatment of ED. The intense competition in this clinical area has had an effect on the patients who enter clinical trials, and whose response ultimately determines the drug's efficacy. Any suggestions that newer agents have better efficacy in subpopulations have to be interpreted with caution.

Tadalafil, vardenafil and apomorphine trials included patients who were previous sildenafil users (if successful) and excluded sildenafil failures. The exact proportion of patients with previous PDE5 exposure should be readily available. In addition, the end points used for the apomorphine studies were different from those of the PDE5 trials, making comparisons difficult. Not until we see head to head trials can we suggest the superiority of one agent over another. Until then, selection should be tailored to those qualities of the drug that may affect patient compliance, safety or side effect profile. 